\title{
Os Municípios Autônomos de Chiapas e o lugar do poder no movimento neozapatista - reflexões sobre a superação do Estado
}

Lucas Spinelli ${ }^{1}$

Resumo: O objetivo desse artigo é discutir a formação e o funcionamento dos Municípios Autônomos Rebeldes Zapatistas (MAREZ) - estabelecidos no estado de Chiapas, sul do México - enquanto base social do movimento neozapatista e projeto alternativo de sociedade à luz do debate teórico travado em torno do conceito de Estado de Antônio Gramsci. O tema central a ser abordado é a autonomia dos MAREZ e as conseqüências das experiências neozapatistas de organização da vida econômica, social e política para as teorias revolucionárias no âmbito do marxismo.

Palavras-chave: Neozapatismo; Estado; Teoria Marxista; Revolução; Autonomia; Gramsci

Abstract: The objective of this article is to discuss the formation and the functioning of the Autonomous Rebellious Zapatistas Comunities (MAREZ) established in the state of Chiapas, south of Mexico, while social base of the neozapatista movement and alternative project of society, by the light of the theoretical discussion on Antonio Gramsci's concept of State. The central subject that will be boarded is the autonomy of the MAREZ and the consequences of the neozapatistas organization's experiences of the economical, social and political life for the revolutionary theories in the context of the Marxism.

Keywords: Neozapatism; State; Marxist Theory; Revolution; Autonomy; Gramsci

\section{O método da revolução: uma introdução}

As teorias de superação do capitalismo passaram por um processo contínuo de reflexão e crítica, ao longo do século XX, no campo das esquerdas e, mais especificamente, dentro do pensamento marxista. As análises constituídas

1 Mestrando em Ciência Política pela Universidade Estadual de Campinas (Unicamp). Correio eletrônico: lucasgespin@ yahoo.com.br

\begin{tabular}{l|l} 
cadernos cemarx, $\mathrm{n}^{\circ} 5-2009$ & 181
\end{tabular} 
pelo marxismo-leninismo ${ }^{2}$ acerca do papel da vanguarda revolucionária balizam as interpretações dos sujeitos da transformação social, desde a revolução russa até os mais recentes levantes populares ocorridos na América Latina. Tendo em vista essa problemática, esse trabalho busca abordar a experiência do movimento neozapatista como mais uma contribuição crítica no âmbito do próprio marxismo, visando problematizar a prática revolucionária leninista centrada no partido de vanguarda.

O movimento neozapatista, organizado inicialmente em torno do Exército Zapatista de Libertação Nacional (EZLN), tem atuado no México desde a década de 1980, e suas ações tornaram-se conhecidas a partir do levante de $1^{\circ}$ de janeiro de 1994, quando surgiu ao mundo, diretamente de Chiapas - o estado mais pobre do país -, para se colocar em guerra aberta contra o neoliberalismo (BORÓN, 2003). Apesar de sua aparição como movimento armado, o reconhecimento da própria inferioridade bélica diante do exército mexicano nunca foi um ponto em questão como demonstram as variadas Declarações da Selva Lacandona ${ }^{3}$. Em pouco tempo, o neozapatismo firmou-se como articulador de um projeto antagônico à democracia vigente no México de várias outras forças e organizações da sociedade civil mexicana. Em entrevista à Revista Atenção (1996, p. 41), Marcos ${ }^{4}$ o principal porta-voz do EZLN, aponta duas matrizes sociais do movimento:

O grupo urbano era pequeno, de orientação marxista-leninista, formado por gente de classe média que viu fechar suas alternativas políticas pelo monopólio do Partido Revolucionário Institucional (PRI). Era uma organização clandestina que procurava crescer com trabalho político, sabendo que um dia iria aderir à luta armada. Como precisava de um lugar para se preparar militarmente, entrou em contato com indígenas de Chiapas que também haviam concluído que a via pacífica havia se esgotado. Da convergência de interesses surgiu o EZLN, em novembro de 1983.

Sobre os grupos que originaram o EZLN, Le Bot (apud ORNELAS, 2005) frisa que tanto os guerrilheiros revolucionários de inspiração marxista-leninista como as

2 Marxismo-leninismo é o termo utilizado para definir o método da revolução desenvolvido por Lênin em $O$ Estado e a Revolução a partir de sua interpretação do aspecto político presente na obra de Marx e Engels, fundamentalmente centrado na tomada do aparelho do Estado dirigida pelo partido de vanguarda revolucionária: “... os partidos leninistas eram essencialmente construídos como elites (vanguardas) de líderes (ou melhor, antes das revoluções serem vencidas, 'contra-elites')..." (HOBSBAWN, 2007, p. 82).

3 Declarações da Selva Lacandona são comunicados oficiais da cúpula do EZLN.

4 Figura mais conhecida do EZLN, o Sub-Comandante Marcos se declara diretamente submetido às decisões do Comitê Clandestino Indígena Revolucionário que reivindica para si a legitimidade das comunidades indígenas em rebelião.

182 Os Municípios Autônomos de Chiapas e o lugar do poder no movimento neozapatista... 
comunidades indígenas e camponesas de Chiapas passaram por um processo conjunto de ressignificação dos sentidos da luta política. De fato, a tomada da guerrilha pelos indígenas e a subordinação dos guerrilheiros às determinações das comunidades locais marcam um processo de ruptura com os pressupostos marxistas-leninistas dominantes nos grupos políticos de esquerda até a década de 1980 no México (CASANOVA, 1996), conformando um amálgama muito específico da realidade latino-americana: luta armada e movimentos sociais não organizados em torno do proletariado urbano.

\section{Chiapas: do foquismo à hegemonia}

Segundo Perry Anderson (1989), Karl Korsch e Gramsci seriam os últimos expoentes da geração de pensadores militantes do marxismo ocidental (entendido como o ramo teórico desenvolvido nos países do capitalismo central) que não condicionavam seus escritos à função acadêmica e científica, mas voltavam seu conceitual à iminência da luta política revolucionária. Segundo Anderson, as gerações seguintes de teóricos marxistas passam a distanciar elaboração teórica e conceitual da prática militante.

Essa teoria gerada na e voltada para a práxis surgiu de forma significativa nos países "não-ocidentais", onde se deram processos de ruptura diretamente vinculados à organização política dos camponeses. Ernesto Che Guevara, figura central para entender o pensamento marxista da esquerda revolucionária latino-americana marcada profundamente pelo legado das guerrilhas e pela revolução cubana - baseou seu foco insurrecional ${ }^{5}$ a partir da crítica aos partidos comunistas enquanto sujeitos exclusivos da revolução.

Novos atores sociais das classes subalternas - não organizados em torno de um partido - passaram a se integrar à estratégia da tomada do poder do Estado pela vanguarda, ainda que a tarefa da direção da revolução pelo partido comunista continuasse presente (GUEVARA, 1987). A figura do camponês é fundamental para compreender as possibilidades de revolução nos países subdesenvolvidos, uma vez que o meio rural coloca as condições objetivas para desenvolver a estratégia da guerrilha: militantes civis e militares diluem-se na massa (HOBSBAWN, 2007). Ao mesmo tempo, os processos de transição característicos das primeiras aberturas

5 Foco insurrecional é o método proposto por Ernesto Che Guevara nos países “onde nem sempre é preciso esperar que se apresentem todas as condições para a revolução: o foco insurrecional pode criá-las" (GUEVARA, E. apud GUEVARA, R., 1987, p. 13). Na prática também se baseia na tomada do Estado, sendo, portanto uma vertente do marxismo-leninismo. 
políticas dos regimes militares, a partir do fim dos anos 1970 nos países da América Latina, lançaram luzes sobre a ascensão política de novas estratégias políticas.

Concomitantemente, estudos sobre Gramsci surgiram como renovação teórica útil à compreensão das novas formas de atuação colocadas pelos atores sociais que irrompiam na cena política para além e através dos partidos de esquerda. Tais atores foram reconhecidos como novos movimentos sociais e possuíam um objetivo: a disputa pela construção da hegemonia político-cultural no âmbito da sociedade civil (DAGNINO, 2000). E é reconhecendo o impacto dos movimentos das comunidades indígenas para a formação do neozapatismo ao longo dos anos 80 e 90 que é necessário pensar, não a ação revolucionária de Lênin, mas a especificidade da luta dos indígenas de Chiapas. Especificidade em que a luta armada é um meio e ora se conjuga, ora dá espaço à construção da hegemonia político-cultural e à busca pela autonomia, no espaço da sociedade civil.

\section{A concepção de Estado na obra de Gramsci}

A concepção liberal, com a qual Gramsci travava debate, apresentava o Estado como sinônimo de governo, responsável pela manutenção da ordem social, a partir do exercício da lei e da repressão: "o estado vigilante”. Mas, segundo Glucksman (1990), Gramsci apontava uma concepção de Estado baseada não apenas na idéia de aparato de repressão, mas também no desenvolvimento da idéia de hegemonia para a garantia da ordem na sociedade:

O fato da hegemonia pressupõe indubitavelmente que se leve em conta interesses e grupos sobre os quais a hegemonia se exerce, que se forme um certo equilibrio de compromisso, isto é, que o grupo dirigente faça sacrifícios de ordem econômica corporativista; mas é evidente que tais sacrifícios e tal compromisso não dizem respeito ao essencial. Porque se a hegemonia é ético-política, ela não pode deixar de ser econômica, ela não pode deixar de ter seu fundamento na função decisiva que o grupo dirigente exerce nos setores decisivos da produção (Gramsci, apud Buci-Glucksman, 1990, p. 100).

A problemática do equilíbrio de compromisso diz respeito à formação da hegemonia como elemento ético-político que não está dissociado do econômico, o que significa dizer que são faces de uma mesma moeda do exercício do poder. A preocupação de Gramsci com essa questão relaciona-se à sua interpretação da revolução russa e do método apresentado por Lênin para a superação do Estado

184 Os Municípios Autônomos de Chiapas e o lugar do poder no movimento neozapatista... 
capitalista. Em uma passagem na qual compara formações estatais diferenciadas pela idéia de ocidente e oriente, Gramsci escreve:

No Oriente, o Estado era tudo, a sociedade civil era primordial e gelatinosa; no Ocidente, havia entre o Estado e a Sociedade Civil uma justa relação e em qualquer abalo do Estado imediatamente descobria-se uma poderosa estrutura da sociedade civil. O Estado era apenas uma trincheira avançada, por trás da qual se situava uma robusta cadeia de fortalezas e casamatas (GRAmSCI, 1980, p. 75).

A idéia de Oriente em Gramsci está pautada na sua leitura acerca das condições que possibilitaram o advento da revolução russa de 1917, a partir da aplicação do golpe definitivo contra o Estado pelo partido comunista, num país onde a sociedade civil era "primordial e gelatinosa". Segundo Lênin, a tomada do poder do Estado era parte fundamental para a tarefa civilizatória do socialismo; uma vez que, ao tomar controle do poder do Estado (poder político), a vanguarda do proletariado (o partido comunista) empregaria os instrumentos de repressão do Estado burguês a favor do proletariado em caráter "educativo" para todas as outras classes sociais. Esta fase socialista, definida sob o conceito de ditadura do proletariado, é um momento de transição em que o Estado civiliza a sociedade para estabelecer o comunismo, até "definhar-se" (LÊNIN, 1987), uma vez que suas funções repressivas terminam. A política para Lênin significa o exercício do poder a partir do Estado - considerado aparelho de dominação de classe -; e o fim da sociedade de classes implica o fim do Estado.

Para Coutinho (1989), Gramsci pensa o entrincheiramento do poder do Estado na sociedade civil a partir da interpretação dos processos históricos e das condições políticas no Ocidente em oposição ao Oriente - relacionados ao processo de "socialização da política" iniciado nos países ocidentais desde o final do século XIX:

A teoria ampliada do Estado em Gramsci (conservação/superação da teoria marxista "clássica" apóia-se nessa descoberta dos aparelhos privados de hegemonia, o que leva nosso autor a distinguir duas esferas essenciais no interior das superestruturas (...). Portanto, o Estado em sentido amplo, "com suas novas determinações", comporta duas esferas principais: a sociedade politica (que Gramsci também chama de 'Estado em sentido estrito' ou de "Estado-coerção"), que é formada pelo conjunto dos mecanismos através dos quais a classe dominante detém o monopólio legal da repressão e da violência,

cadernos cemarx, $\mathrm{n}^{\circ} 5-2009 \quad 185$ 
e que se identifica com os aparelhos de coerção sob controle das burocracias executiva e policial-militar; e a sociedade civil, formada precisamente pelo conjunto das organizações responsáveis pela elaboração e/ou difusão das ideologias, compreendendo o sistema escolar, as igrejas, os partidos políticos, os sindicatos, as organizações profissionais, a organização material da cultura (revistas, jornais, editoras, meios de comunicação de massa), etc. (CoutinHo, 1989, p. 76-7).

A sociedade civil de Gramsci - uma das faces do Estado ampliado ocidental seria, portanto, uma complexa e "robusta cadeia de fortalezas e casamatas" composta por aparelhos privados de hegemonia. Coutinho investe na idéia de que, para Gramsci, a instância dos aparelhos privados de hegemonia (a sociedade civil) seria o espaço primordial e preferencial para as classes subalternas obterem a hegemonia, devido principalmente à fruição de uma autonomia funcional e material em relação ao Estado (sociedade política e esfera da coerção). Para a prática política transformadora e conseqüente, deveria haver um deslocamento do foco da ação política, fundamentado no fato de o lugar do poder não se concentrar na sociedade política (o Estado estrito), mas em uma ampla rede de instâncias e aparelhos denominados em seu conjunto como sociedade civil - a face ampliada do Estado nas sociedades capitalistas complexas.

Isso não quer dizer que a sociedade civil e os aparelhos de hegemonia se constituam como espaço não-coercitivo e pacífico de construção consensual da hegemonia, como certas leituras da obra de Gramsci podem sugerir. Para Liguori (2005), Bobbio enfatiza o conceito de sociedade civil em detrimento da idéia de hegemonia de Gramsci, conferindo-lhe autonomia e sugerindo uma ruptura gramsciana com a suposta predominância da estrutura econômica sobre a superestrutura (sociedade civil e sociedade política) do marxismo. Para Bianchi (2007), a interpretação da obra de Gramsci efetuada por Bobbio acaba por definir uma oposição entre hegemonia (pólo da superestrutura assumida como consenso) e ditadura (pólo da superestrutura assumida como coerção), de onde decorre a atribuição de um caráter liberal-positivo à sociedade civil, em oposição à negatividade do Estado (legislador repressivo, mas necessário para assegurar as regras do jogo), sob clara influência do pensamento tocquevilliano.

A interpretação de Bianchi dos Cadernos do Cárcere leva a ressaltar dois sentidos de sociedade civil recorrentes na obra de Gramsci:

No primeiro, a sociedade civil está associada às formas de exercício e afirmação da

$186 \quad$ Os Municípios Autônomos de Chiapas e o lugar do poder no movimento neozapatista... 
supremacia de uma classe sobre o conjunto da sociedade. Faz parte de um programa de pesquisa que visa esclarecer não só os processos de revolução burguesa e de fundação de um novo Estado, como a longevidade e fortaleza das instituições políticas do Ocidente capitalista e a possibilidade de instauração de uma nova ordem social e política. No segundo sentido, frequentemente apresentado entre aspas, destaca-se a capacidade de iniciativa econômica que o Estado possui no capitalismo contemporâneo (BIANCHI, 2007, p. 43).

A sociedade civil aparece em Gramsci não apenas como uma instância político-cultural de caráter afirmativo de construção hegemônica, mas também como instância da atividade econômica, dos interesses materiais e da propriedade privada regulados pela coerção e pela legislação estatal:

Como na realidade factual sociedade civil e Estado se identificam, deve-se considerar que também o liberismo é uma 'regulamentação' de caráter estatal, introduzida e mantida por caminhos legislativos e coercitivos: é um fato de vontade consciente dos próprios fins, e não expressão espontânea, automática, do fato econômico (GRAMSCI, apud BIANCHI, p. 43).

Bianchi considera assim que a ampliação do conceito de Estado só pode ser compreendida a partir da elaboração da idéia de hegemonia como unidade-dual da força e do consenso, que compreende uma relação dialética entre sociedade civil e sociedade política, estrutura e superestrutura, ditadura e hegemonia; mas de forma alguma condizente com um predomínio de um dos pólos em detrimento do outro. A sociedade civil não é o pólo exclusivo do consenso e a sociedade política não é o pólo exclusivo da coerção, mas ambas se integram organicamente na unidade-dual própria do pensamento dialético gramsciano.

\section{O Estado Ampliado e a experiência neozapatista}

Enquanto movimento indígena e camponês associado ao histórico legado revolucionário das guerrilhas latino-americanas, o neozapatismo retoma a crítica do partido de vanguarda como sujeito revolucionário exclusivo. Ao mesmo tempo, concentra suas ações na construção da hegemonia na sociedade civil e da autonomia em detrimento da tomada de assalto do poder do Estado (ZERMEÑO, 1997), sendo objeto de debates acerca de seu caráter transformador dentro do campo teórico marxista. 
Para Holloway (2003), o neozapatismo rompe com a tradição instrumental do marxismo científico que considera o Estado como o local privilegiado da revolução, ao negar o objetivo da tomada do poder (situado no Estado). O fetichismo, que forma as relações sociais capitalistas e as relações de poder do Estado nessa sociedade, constitui-se para Holloway como categoria central para desenvolver a idéia de que nenhuma revolução pode ser capaz de romper com a ordem social do Capital se não romper com ela em seu cotidiano. O tempo da revolução deve escapar do processo de identificação, apropriação, domesticação e racionalização do capitalismo. Torna-se, assim, absurdo que um movimento que tem por objetivo superar o capitalismo tome para si as estruturas do Estado existente no modo de produção capitalista.

Em debate com Holloway, e alguns apontamentos oficiais dos zapatistas, Atílio Borón (2003) aponta dois problemas observados a partir das proposições do EZLN. Primeiramente, defende a permanência do Estado-Nação como lugar central da reprodução do Capital, ao contrário do que as teorias da descentralização do poder e desterritorialização do capitalismo possam sugerir. Em segundo lugar, Borón ressalta que Lênin considerava a revolução dividida em uma fase de "tomada do poder" e uma fase de "efetivação da revolução" - dada por ações civilizatórias do socialismo com o uso da máquina do Estado burguês. E retoma Gramsci ao considerar o duplo caráter necessário ao movimento, que busca o exercício do poder na sociedade capitalista: vocação para o poder e direção moral e intelectual - conteúdo civilizatório. Ou seja, Borón considera que se o neozapatismo ignora a centralidade do Estado na sociedade capitalista, não se apresenta apto ao poder, embora seja detentor da legitimidade (direção ética e intelectual). E não se apresentar apto ao poder significa se sujeitar ao funcionamento da sociedade capitalista, através da cooptação ou da repressão.

Abordando outro aspecto do movimento, Raúl Ornelas (2005) ressalta o caráter de retroalimentação entre o EZLN e as comunidades autônomas de Chiapas, que não apenas se servem do exército insurgente, mas compõem suas fileiras de combatentes e dirigem suas ações táticas e estratégicas através de seus representantes no Comitê Clandestino Revolucionário Indígena (CCRI). A vanguarda política, que tem por compromisso levar a consciência às massas com o objetivo de tomar o poder do Estado para implementar um governo de transição em nome daquelas, é substituída aqui por um núcleo militar - o Exército Zapatista de Libertação Nacional - que se submete às determinações do conjunto das comunidades rebeldes, como forma de garantir a auto-organização autônoma das próprias comunidades. O EZLN não existe

188 Os Municípios Autônomos de Chiapas e o lugar do poder no movimento neozapatista... 
por si só.

\section{O neozapatismo para além da luta armada}

O movimento neozapatista não toma para si a missão da tomada do poder do Estado, mas tem seguidamente estimulado um amplo debate regional e global com vistas a construir estratégias de luta contra o capitalismo (Jessop, 2002). Nesse sentido, a constituição do neozapatismo como um movimento social, que ultrapassa o âmbito militar do exército insurgente e se fundamenta num aglomerado de municípios "autônomos em rebeldia" em relação ao Estado mexicano, é fundamental para compreender porque o EZLN não se propõe tomar o poder do Estado:

A formação e o funcionamento dos Municípios Autônomos Rebeldes Zapatistas (MAREZ) ilustram os alcances da luta zapatista no horizonte da transformação social. Estas iniciativas têm um caráter de reagrupamento territorial a partir de vários tipos de nexos históricos: o pertencimento a uma etnia, os trabalhos em comum, a situação geográfica, as relações de intercâmbio. Diferentemente das divisões arbitrárias dos municípios "oficiais", os municípios rebeldes são o resultado da afinidade entre suas populações. Esta ruptura coloca um desafio radical frente ao poder, pois desloca o conflito da arena política para a questão fundamental do controle do território (ORNELAS, 2005, p. 134).

Ornelas (2005) enfatiza dois elementos que sugerem uma relativa autonomia dos neozapatistas em relação ao Estado capitalista do México, efetivados no dia-a-dia das comunidades de Chiapas: o processo de criação autogestionada da vida social e a construção das condições materiais para a resistência. A autonomia do movimento passa necessariamente pela práxis econômica e política integrada socialmente e autogerida no dia-a-dia das comunidades - a base dos municípios autônomos zapatistas ${ }^{6}$, de onde são definidos representantes em caráter rotativo para o Conselho Municipal, a mais alta instância local de decisão:

Estes representantes participam em alguma das "comissões" ou "comitês" encarregados de tarefas específicas: justiça, assuntos agrários, saúde, educação,

6 Municípios Autônomos Rebeldes Zapatistas (MAREZ). O estabelecimento de trinta novos municípios - em substituição aos municípios oficiais - se deu após o fim da trégua com o governo federal de Ernesto Zedillo, quando os habitantes locais reorganizaram o espaço do território zapatista (ORNELAS, 2005). Desde 2003, os MAREZ são articulados pelas Juntas do Bom Governo, a fim de nivelar as disparidades entre cada município.

cadernos cemarx, $\mathrm{n}^{\circ} 5-2009 \quad 189$ 
cultura, produção, entre as mais comuns (...). É essa instância colegiada que deu vida aos Municípios Autônomos desde 1994. Paulatinamente os Conselhos Autônomos consolidaram sua presença e autoridade graças às iniciativas para melhorar a vida das comunidades e as suas práticas de 'bom governo', isto é, privilegiar a busca de acordos em vez do enfrentamento ou da repressão, assim como a aplicação do direito 'consuetudinário', que prefere a reparação do dano à sanção (...). Nesse sentido os Conselhos Autônomos têm desempenhado um papel essencial no desenvolvimento da luta zapatista. No interior das comunidades, o projeto autonômico ganhou legitimidade graças às tarefas de saúde, educação, culturais e produtivas que permitiram melhorar as condições de vida (ORNELAS, 2005, p. 136-7).

Na medida em que disputa e busca a autonomia de suas próprias instâncias de decisão política e de organização econômica e social, os neozapatistas estariam efetivando um dos "novos espaços autônomos das classes subalternas e da negação dos espaços políticos das classes dominantes" (Bianchi, 2007, p. 41)? Ao mesmo tempo, nos termos de Gramsci relativos ao "conteúdo ético-moral do príncipe moderno", poder-se-ia dizer que o neozapatismo apresenta-se como grupo capaz de fazer seus interesses particulares se "nacionalizarem", apresentando a "proposta civilizatória alternativa ao capitalismo" (HOLLOWAY \& CECEÑA apud ORNELAS, 2005)? O neozapatismo não se propõe a criar o próprio espaço político enquanto projeto antagônico ao poder institucional e repressivo do Estado, nascido e ativo nas beiradas do "Estado ampliado" oficial do poder federal?

A unidade dual coerção-consenso, estrutura e superestrutura, que trespassa a concepção de hegemonia, fundamento do conceito de Estado na obra de Gramsci (BIANCHI, 2007), é necessária aqui para uma análise da experiência neozapatista, uma vez que os MAREZ parecem se manter em paralelo ao Estado Mexicano, ao mesmo tempo em que são base social e razão de ser do EZLN. Nesse sentido, a análise da experiência neozapatista como movimento que busca "firmar-se como novo Estado" diz respeito não apenas aos problemas específicos enfrentados pelos neozapatistas em Chiapas, mas aos desafios colocados aos fundamentos da esquerda ao redor do globo. A serem ditos: a concepção de que a luta revolucionária deve buscar a tomada do Estado - o centro do exercício do poder das classes dominantes no sistema capitalista -, tornado autônomo pela ação do partido revolucionário, para empreender um governo dirigido ao comunismo; e a idéia do partido de quadros como sujeito revolucionário exclusivo.

190 Os Municípios Autônomos de Chiapas e o lugar do poder no movimento neozapatista... 


\section{A autonomia e o poder dual em Chiapas}

Desde o levante de $1^{\circ}$ de janeiro de 1994, o movimento neozapatista caracterizou-se por ser um grupo armado que travou uma guerra aberta de curta duração com o Estado mexicano e que, ao longo dos anos, tem apresentado estratégias de articulação com outros movimentos sociais mexicanos e contra o Estado. Ao mesmo tempo, continuam as ofensivas militares e paramilitares contra neozapatistas e simpatizantes (HILSENBECK, 2007). Diante disso, o EZLN justifica sua própria existência pelo caráter preventivo: garantia de defesa dos MAREZ e dos seus territórios, ao passo que nega a tomada do poder do Estado.

$\mathrm{Na}$ sua atuação cotidiana, os neozapatistas praticam a autonomia como a melhor e talvez a única possibilidade de romper com o capitalismo e o Estado atual. O território zapatista constitui-se dentro de uma zona em litígio no sul do México; as comunidades autônomas compõem o EZLN e estão organizadas em torno dos Caracoles $^{7}$, sedes da vida social das comunidades indígenas-camponesas de Chiapas, em oposição às instâncias de poder dos governos oficiais; e por fim, a posse da terra pelas comunidades e o trabalho coletivo possibilita a autonomia material. Assim, o objetivo assumido pelo EZLN é servir às comunidades autônomas de Chiapas, consideradas a base da auto-suficiência econômica e social do movimento (MARCOS apud ORNELAS, 2005).

Tendo território definido, leis e auto-organização política e social, elemento de autodefesa (o EZLN), sistema de produção voltado ao abastecimento interno e redes de troca (Ornelas, 2005), os neozapatistas não poderiam ser considerados formadores de um poder dual em relação ao Estado capitalista mexicano? Um novo poder, compreendido pelos MAREZ, articulado pelas Juntas do Bom Governo e defendido pelo EZLN, o elemento de autodefesa dos habitantes locais?

Para responder a estas questões é necessário: a) compreender o processo de formação do neozapatismo ao longo dos anos 1970, 1980 e 1990 e suas (des) continuidades; b) analisar os processos históricos de ruptura ocorridos após o levante de $1^{\circ}$ e janeiro de 1994, abarcando a formação dos MAREZ em dezembro do mesmo ano; analisar os espaços de diálogo institucionais com o governo e a sociedade civil, até a formação das Juntas do Bom Governo em 2003, articuladoras dos MAREZ; c) analisar a experiência dos MAREZ, a autonomia e suas limitações, à luz do debate

7 Sedes das Juntas de Bom Governo, onde são realizadas as reuniões de articulação das solidariedades entre representantes dos 38 MAREZ, de organizações civis simpatizantes e militantes de movimentos sociais.

cadernos cemarx, $\mathrm{n}^{\circ} 5-2009 \quad 191$ 
teórico em torno da concepção de revolução e poder dual no âmbito do marxismo ${ }^{8}$.

Para efeito de conclusão, este artigo sugere que o movimento neozapatista se distingue "menos por los objetivos materiales específicos, ni por la radicalidad de las reivindicaciones materiales, sino por que se enfrenta conscientemente a las formas sociales capitalistas transciendendolas" (HIRSCH, 2005, p. 174). Nesse sentido, é na análise do funcionamento dos MAREZ, e no caráter político da sua existência num território "autônomo", que está o fundamento da estratégia neozapatista de enfrentamento do Estado e do regime capitalista. A experiência da autonomia dos municípios autônomos zapatistas de Chiapas seria revolucionária não em si mesma, mas por romper com a forma política do capitalismo: por romper com o Estado e o político separados da sociedade e dos sujeitos. Por territorializar e materializar o poder político na autogestão da vida e da luta.

\section{Bibliografia}

Anderson, Perry. Considerações sobre o marxismo ocidental. São Paulo: Brasiliense, 1989.

Altmann, Werner. "A Rebelião indígena de Chiapas: o anti-neoliberalismo orgânico da América Latina". In: BARSOTTI, Paulo; PERICÁS, Luiz Bernardo (Org.). América Latina: história, idéias e revolução. São Paulo: Xamã, 1998.

Bianchi, Alvaro Gabriel. "Gramsci além de Maquiavel e Croce: Estado e Sociedade Civil nos 'Quaderni del Carcere'." In: Utopia y Praxis Latinoamericana, $\mathrm{n}^{\circ}$ 36, 2007.

Borón, Atilio. "A selva e a polis: interrogações em torno da teoria política do zapatismo.” In: Borón, Atilio. Filosofia política marxista. São Paulo: Cortez, 2003.

Buci-Glucksman, Christine. Gramsci e o Estado: por uma teoria materialista da filosofia. Rio de Janeiro: Paz e Terra, 1990.

\footnotetext{
8 Reconhecemos que, para tratar a problemática do poder dual, é necessário desenvolver a discussão da autonomia e da autogestão como formas de luta revolucionária. Em futuros trabalhos, pretendemos desenvolver tal discussão a partir dos debates sobre o caráter da Comuna de Paris travado entre Marx, Prudhon e Bakunin, passando pelas propostas de comunismo conselhista de Pannekoek e a crítica de Lênin à sua doença infantil, até os escritos de Rosa Luxemburgo, Gramsci e Karl Korsch sobre as experiências dos conselhos de soldados e operários. Comparações com experiências de autonomia e autogestão no campo podem ser exploradas para um debate teórico entre marxismos e outras correntes políticas da esquerda revolucionária. A luta dos movimentos sociais camponeses e indígenas na América Latina é outro caminho a ser explorado, uma vez que aqueles buscam territorializar sua autonomia política.

\begin{tabular}{l|l} 
& \\
\hline 192 & Os Municípios Autônomos de Chiapas e o lugar do poder no movimento neozapatista...
\end{tabular}
} 
CAsanova, Pablo González. "Causas da rebelião em Chiapas". In: Olho da História revista de História Contemporânea. Salvador, nº 3 dezembro de 1996. Disponível em www.ufba.br/ revistao/03casano.html.

Coutinho, Carlos Nelson. Gramsci: um estudo sobre seu pensamento político. Rio de Janeiro: Editora Campus, 1989.

Dagnino, Evelina. "Cultura, cidadania e democracia: A transformação dos discursos e práticas na esquerda latino-americana". In: Alvarez, Sonia. Dagnino, Evelina. \& Escobar, Arturo. (Org.) Cultura e politica nos movimentos sociais latinoamericanos - novas leituras. Belo Horizonte: Editora UFMG, 2000.

Gramsci, Antonio. Maquiavel, a política e o Estado moderno. São Paulo: Editora Brasiliense, 1980.

Guevara, Roberto. "Prólogo". In: Guevara, Che. Textos revolucionários. São Paulo: Edições Populares, 1987.

HilsenBeCK, Alexander. "Abaixo e à esquerda: uma análise histórico-social da práxis do Exército zapatista de Libertação Nacional". Marília, 2007. Dissertação (Mestrado em Ciências Sociais). Faculdade de Filosofia e Ciências, Universidade Estadual Paulista.

HiRch, Joachin. "Qué significa el Estado? Reflexiones acerca de la teoría del Estado capitalista". In: Revista de Sociologia e Política, n 24, 2005.

Hobsbawn, Eric. Era dos extremos: O breve século XX 1914-1991. São Paulo: Companhia das Letras, 2007.

Holloway, John. Mudar o mundo sem tomar o poder. São Paulo: Contraponto, 2003.

JEssop, Bob. "Globalização, regionalização, mercado e o Estado: entrevista com Bob Jessop". In: Currículo sem fronteiras, vol 2, n 2, 2002.

LÊNIN, Vladimir. O Estado e a revolução. São Paulo: Editora Hucitec, 1987.

LigUORI, Guido. "Estado e sociedade civil: entender Gramsci para entender a realidade" In: Coutinho, Carlos Nelson; TeixeIRA, Ana Paula. (Orgs.). Ler Gramsci, entender a realidade. Rio de Janeiro: Civilização Brasileira, 2005

Marcos. In: Ortiz, Pedro (entrevistador) "Ya basta". In Revista Atenção. São Paulo, ano $2, \mathrm{n}^{\circ} 8,1996$.

Ornelas, R. "A Autonomia como eixo da Resistência Zapatista - Do levante

cadernos cemarx, $\mathrm{n}^{\circ} 5-2009 \quad 193$ 
armado ao nascimento dos Caracoles". In: CeCEnÃ, A. E. (Org) Hegemonias e Emancipações. $1^{a}$ edição. Buenos Aires: CLACSO, 2005

Zermeño, S. "O Levante Zapatista no México". In: Praga - revista de estudos marxistas. São Paulo: Boitempo, nº 2, 1997.

194 Os Municípios Autônomos de Chiapas e o lugar do poder no movimento neozapatista... 